\title{
A Cost Efficiency Analysis of Flood Proofing Measures for Hydraulic Risk Mitigation in an Urbanized Riverine Area
}

\author{
Ugo Ventimiglia $^{1, *}$, Angela Candela ${ }^{2}$ and Giuseppe Tito Aronica ${ }^{1}$ (D) \\ 1 Department of Engineering, University of Messina, Contrada Di Dio (Villaggio S. Agata), \\ 98166 Messina, Italy; giuseppetito.aronica@unime.it \\ 2 Department of Engineering, University of Palermo, Viale delle Scienze, 90128 Palermo, Italy; \\ angela.candela@unipa.it \\ * Correspondence: uventimiglia@unime.it
}

Received: 18 May 2020; Accepted: 20 August 2020; Published: 26 August 2020

\begin{abstract}
Non-structural measures for flood risk mitigation are often more economically accessible, easier to implement, and are highly effective, especially in view of the pursuit of risk resilience objectives. Among the non-structural measures, more importance is increasingly being attributed to flood proofing interventions. There are two main types of flood proofing: dry proofing and wet proofing. An example of dry proofing is shielding, which involves the use of flood barriers that can be installed in the entrances of buildings or outside the buildings in order to avoid contact with the houses and deviate the water flow. Their use must be supported by a detailed hydraulic analysis to ensure the correct design is used. This kind of intervention also avoids inducing a feeling of false security (the levee effect) in the exposed population, and therefore contributes to increasing their resilience. The aim of the work presented here is to determine an optimal combination of and choice between different types of structural and non-structural measures through the development of a methodology for assessing the real efficiency levels of different measures, using a cost-benefit analysis (CBA) and starting from the estimation of the direct flood damage. The application of the CBA to a case study of the Mela river in northeastern Sicily, which suffered a flooding event in October 2015, is supported by the determination of the real damages after the flood and the modeling of the same damages for alternative scenarios. The results affirm the possibility of reducing or avoiding some of the damage using the proposed flood proofing measures instead of classical ones.
\end{abstract}

Keywords: flood proofing; flood inundation; flood risk management; cost-benefit analysis

\section{Introduction}

Floods are among the most destructive natural disasters around the world. They can cause billions of dollars of damage, as well as the deaths of thousands of people, as occurred in 2017 [1]. There are several classifications of flood hazards, including river floods, flash floods, and local inundations caused by extreme precipitation. In all countries around the world, the extent of the damages from flood events has decreased, rather the frequency and severity of flood risks have increased due to significant global changes. There are many reasons for this situation, including increases in the value of the affected properties and economic activities in areas subject to flood risks, demographic increases, and the increasingly intensive use of land in the aforementioned areas, resulting in a tendency to overestimate capacity of existing protective measures [2].

Flood impacts were not felt to the same extent in the past as they are today, as smaller numbers of people previously inhabited these affected areas and there was far less pressure from human activities in flood-prone areas. As with precipitation, high floods have a high return period, so it is impossible 
to control all floods-only the damage can be reduced. Different approaches can be taken for flood management, including attempts to modify a flood (structural approach), the susceptibility to flood damage, or the loss burden, or by preparing for and bearing the loss (non-structural approach).

For a long time, flood prevention has been entrusted to structural interventions, which allow the flood managers to control and contain floods. In many geographical areas, however, the same interventions are not possible, either because of territorial constraints or because of the associated high costs, meaning these approaches are often not sustainable as there is not reasonable balance between costs and benefits [3,4].

The Flood Risk Management Plan established by European Directive 60/2007 provides for the implementation of structural and non-structural interventions in order to contain flood risks in areas where the potential risk is deemed significant, aiming to reduce the potential negative consequences for human health, the affected territory, assets, the environment, cultural heritage, and economic and social activities.

A comparison between the types of interventions requires a correct assessment of the damages resulting from a flood, which is often quite complex, as this depends on the characteristics of the flooding in terms of the water depth, flood velocity, possible presence of sediment, and above all on the vulnerability and exposure characteristics of the assets located in the at-risk area.

In assessing hydraulic risk, it is essential to estimate the potential damage that can be caused by flood events in order to identify the interventions that can be carried out as part of a cost-benefit analysis. Under some river basin conditions, the introduction of non-structural methods to limit flood damage may be more cost-effective than alternatives involving structural methods.

Due to the great variability of flood-prone areas in terms of climate, urbanization, and morphological characteristics, it is rather difficult to define any standard approach to the application of these measures for flood management of the flood-prone areas. To define an implementable floodplain management policy in order to address flooding problems, solutions must be identified reflecting the current economic, social, and environmental value of the area. The plan should take into account a high degree of protection and minimization of residual risk with respect to hazards to human life, as well as the environmental value of the area. Flood control includes different aspects of flood management as flood proofing measures, involving structural measures and their operation, as well as non-structural measures, which do not involve structural work $[5,6]$.

Several studies have assessed flood damages at different scales, ranging from local to regional and macro area scales [7-11]. Such assessments, however, are often limited in evaluating the flood impacts due to the absence of a global database of flood damage functions, which would be used to translate flood water levels into direct economic damage. Usually, the direct flood damage is evaluated using depth-damage curves, which estimate the flood damages that would occur at specific water depths per asset or per land use class.

Regarding the estimation of the unit costs of flood adaptations, many improvements have been made in recent years for flood management measures. In relation to flood protection measures, several authors have estimated the flood adaptation costs for global cities, such as Linham et al. [12] and Lasage et al. [13], providing detailed estimates for flood protection in cities such as New York, Los Angeles, and Ho Chi Minh City and analyzing cost measures for flood proofing of individual buildings.

In an assessment, it is necessary to identify the risk level (hydraulic) for the current situation, then consider the implementation of interventions, and finally decide which is the most convenient and viable alternative solution. In the case of flood mitigation interventions, the costs and benefits can be characterized as follows. Firstly, the direct costs must be asses, which relate to the costs of the infrastructure that is aimed at mitigating flood impacts or protecting the inhabited centers and infrastructure from floods. Secondly, in connection with these costs, the most important benefits are the defense of settlements and buildings against the danger of flooding. In this sense, an approximation of the (direct) benefits of the works for the hydraulic arrangement is given in relation to the damages derived from flood events, which are avoided thanks to the aforementioned interventions. Therefore, 
the cost-benefit analysis makes it possible to assess the positive impacts (benefits) and negative aspects (costs) of the proposed policy actions in monetary terms, in order to calculate the net benefits derived from the implementation risk mitigation measures.

Based on these considerations, a methodology for assessing the real effectiveness of different flood interventions was set up through a cost-benefit analysis, starting from an estimate of the direct flood damage, in order to provide a knowledge base for interpretation and judgment of the feasibility of certain elements.

This methodology has been applied on a real case study of the Mela catchment, which is located in the northeastern part of Sicily. In October 2015, the valley part of this catchment was affected by a significant flood inundation, which caused considerable damages to the agricultural areas and to two villages located along the river course.

\section{Case Study}

The Mela river is located in the northeastern part of Sicily, between the cities of Milazzo, Santa Lucia del Mela, and Barcellona. The catchment has an extension of about $70 \mathrm{~km}^{2}$ and reaches $1224 \mathrm{~m}$ s.1.m (above sea level), with a mean slope of $4.2 \%$ (Figure 1). The longest drainage path is around $21.5 \mathrm{~km}$ and the concentration time is equal to $2.9 \mathrm{~h}$.

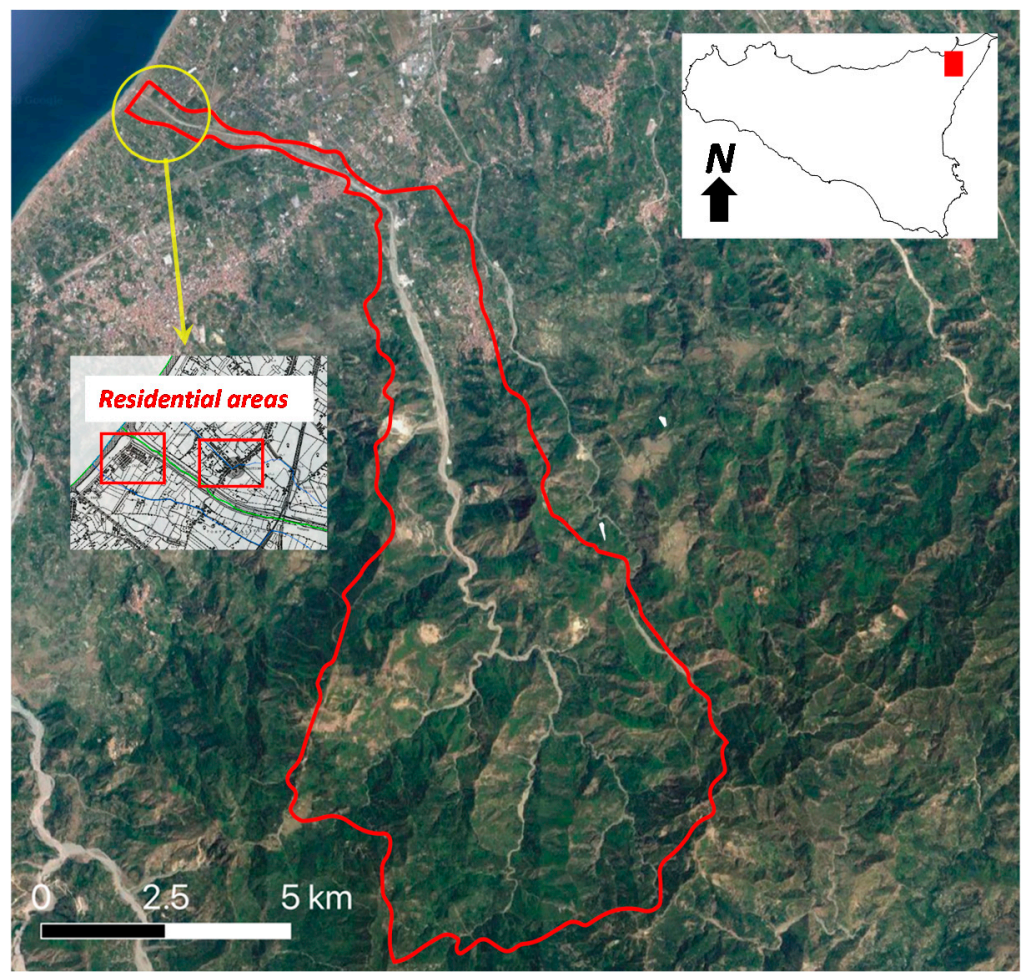

Figure 1. Mela catchment and study area (yellow circle).

The climate is Mediterranean, characterized by a dry season that goes from May to September, and by rainy days of high intensity and short duration. The average annual precipitation rate is about $904 \mathrm{~mm}$, of which about $83 \%$ occurs in the rainy season, while the remainder occurs in the dry season. Over the years, several flash floods have hit the same area, with the last one occurring in 2015.

In October 2015, the valley area of the catchment downstream of the railway crossing (Figure 2, red circle) was affected by a flooding event that caused considerable damage to the residential and neighboring agricultural areas. The extension of the inundated area (Figure 2) was obtained after a post-event survey using a UAV (unmanned aerial vehicle) imager (courtesy of Messina Metropolitan City Civil Protection). 


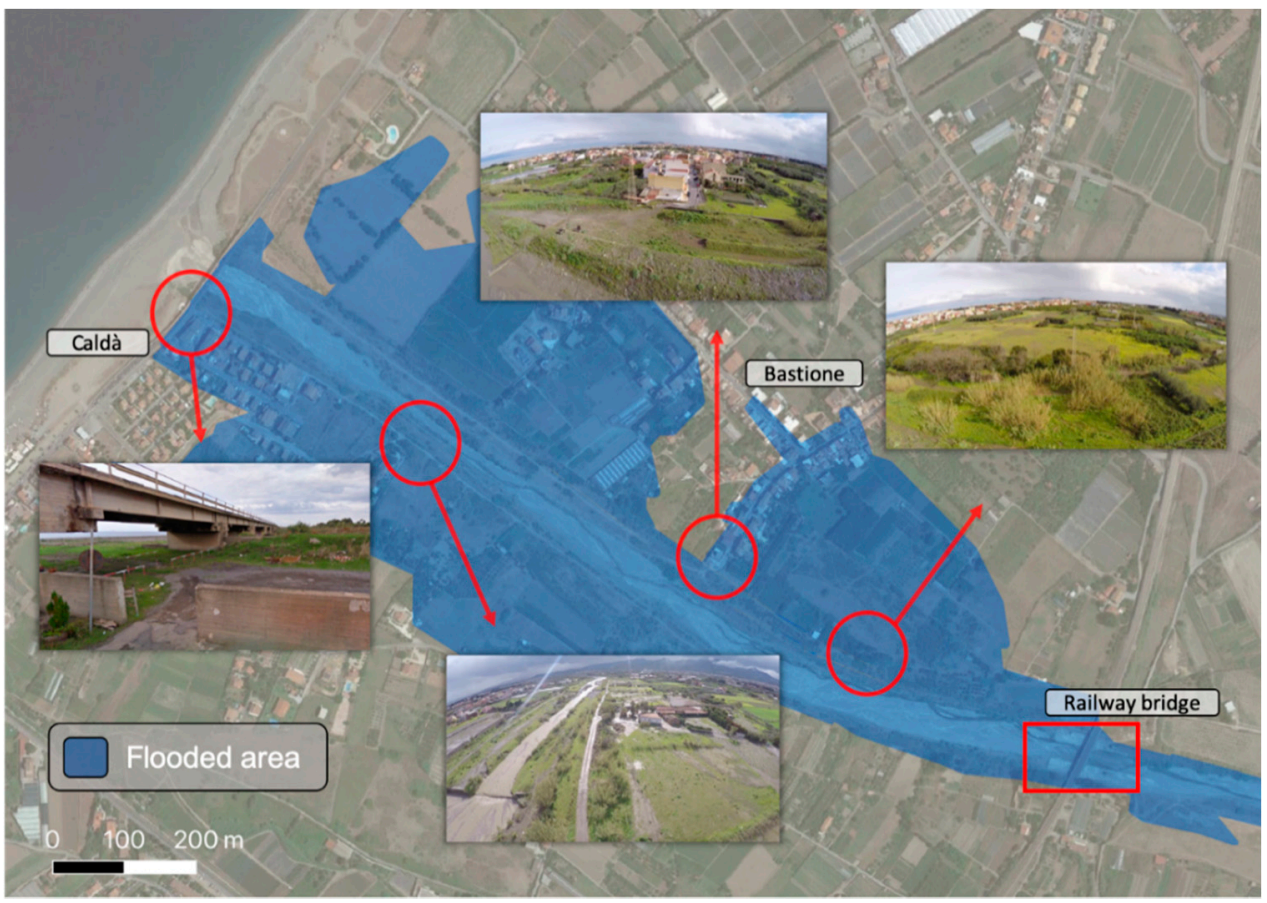

Figure 2. Historical inundated area during the event of October 2015, with evidence of the flooding source points (red circles).

Along the river course on both sides, a system of masonry and concrete levees is in place, with the height varying between 2 and $4 \mathrm{~m}$ and with some discontinuities (red circles in Figure 2), which contributed to the inundation of the surrounding agricultural and residential areas (Caldà and Bastione villages in Figure 3).

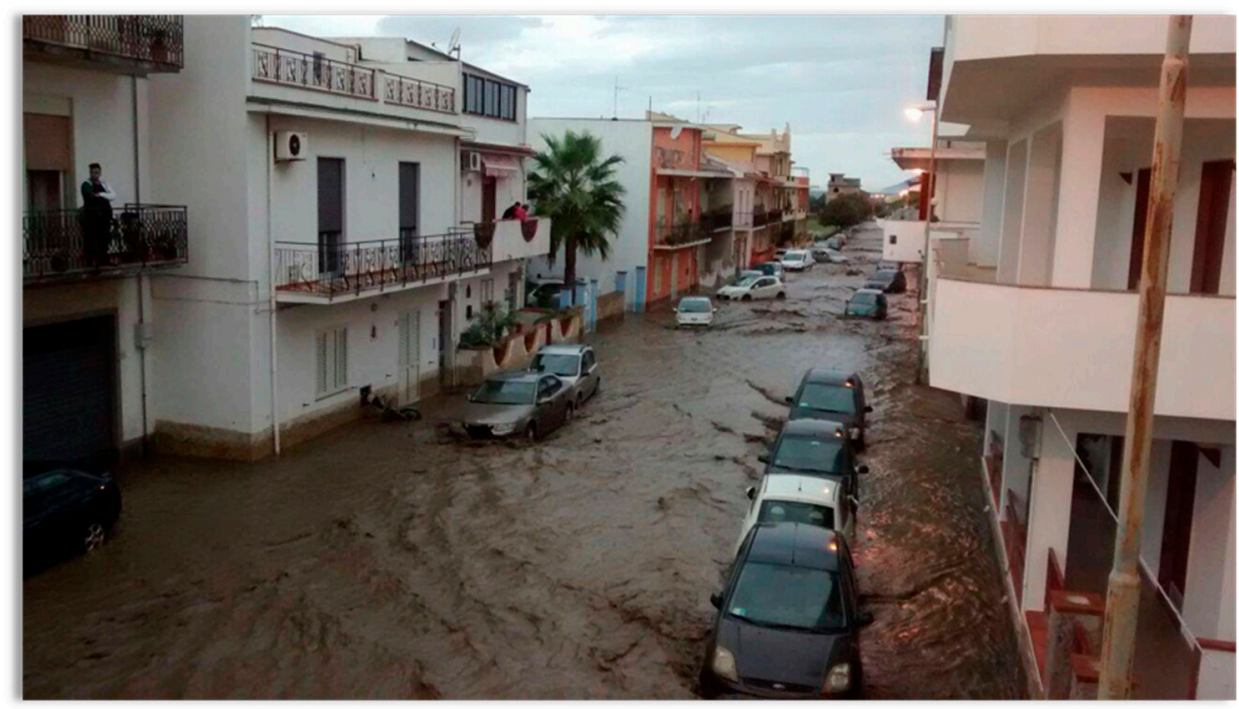

Figure 3. Damage to the village of Bastione caused by the flood event of October 2015.

\section{Methodology}

A methodology for assessing the real effectiveness of different flood proofing measurements was set up through a cost-benefit analysis, starting from an estimate of the direct flood damage in both residential and agricultural areas. Particularly, the cost efficiency levels of three typologies of measures was addressed: two dry flood proofing measures, i.e., flood barriers and flood gates, both of which can 
reduce the potential for flood damage by reducing the probability that a building's interior will be flooded [14]; and one structural measure, i.e., the reconstruction of the levee system.

The cost-benefit analysis (CBA) was adopted in this study in order to provide appropriate information to support the choices of the various mitigation measures proposed.

The methodological objective of the CBA is the comparison of benefits and costs associated with the implementation of a measure, considering measures in both agricultural and residential areas. The aim of this comparison is to determine whether the mitigation measures produce an increase in the level of well-being of a community, so as to evaluate the implementation of the measure. Therefore, different available alternatives are compared by analyzing the advantages (benefits) and disadvantages (costs), which have to be calculated or estimated. This information can be expressed as a number, usually a monetary figure, so that all the quantities that can be considered are homogeneous and directly comparable [15].

Benefits are represented by the reduction of the total direct flood damages as a consequence of specific and relevant risk mitigation measures, while costs are the total costs of building or implementing these mitigation measures.

The evaluation of the total damage caused by the flooding in both agricultural and residential areas was achieved by using specific damage-depth curves (damage curves).

For agricultural areas, the damage is related to a loss in output when the yield is affected by floods. Potential damage functions were obtained based on the methodology proposed by the Joint Research Centre, considering both "new" costs (replacement), and productivity costs [16]. Concerning the damage to buildings in residential areas, instead the approach proposed by [17] was used.

In the present study, the CBA was carried out for different flood risk mitigation scenarios in potentially at-risk areas based on direct flood damages.

For each scenario, a detailed hydraulic analysis was carried out using a two-dimensional flood propagation model in order to obtain maps of flooded areas relating to the different flood mitigation scenarios [18].

In addition to the current scenario (no intervention), the three investigated scenarios, each related to different flood risk mitigation solutions, were as follows:

- Scenario 1: Reconstruction of the existing levees along the watercourse;

- Scenario 2: Installation of flood barriers of different sizes (heights of 150 and $250 \mathrm{~cm}$ );

- Scenario 3: Installation of flood doors and flood windows.

\section{Results and Discussion}

The first step for the CBA is the evaluation of the benefits associated with the intervention scenarios. Actually, the quantification of the benefits required knowledge of the flood hazard scenarios (spatial distribution of inundation depths obtained as outputs of hydrodynamic model simulations) to be used as inputs for the depth-damage curves.

The multilevel flood propagation 2D (MLFP-2D) model $[19,20]$ was used for the hydrodynamic simulation; it is a hyperbolic model based on the de Saint-Venant equations, with convective inertial terms neglected. Hydraulic resistances are expressed via the Chezy-Manning formula, while Manning's roughness coefficient is the unique parameter of the model.

The model inputs consist of the flood hydrographs upstream of the area domain, while the outputs are the spatial distributions of the water depths and flow velocities.

The equations of the 2D flood propagation model are solved using a finite element technique, with triangular meshes characterized for the area under study by 13,953 nodes and 26,628 elements, so as to reproduce the complex topography of the area (natural and built-up areas, presence of infrastructures, obstacles, etc.). 
Regarding the model parameters, one Manning coefficient for each triangular element could be chosen, however as a robust basis for the assignment of those coefficients was lacking, the entire domain was discretized into two "roughness" regions, i.e., the riverbed and floodplain.

Further, despite the differences (natural areas versus built-up areas), the floodplain was considered homogenous in terms of hydraulic roughness because the built-up areas have a small extension in comparison with the natural areas, and hence the influence of the Manning coefficient's spatial distribution within it is negligible. Further, during the flooding, the transported debris settles on the roads between houses, meaning the final roughness is actually comparable to that of the natural areas.

Regarding the Manning roughness coefficient, two calibrated values were considered, i.e., $0.038 \mathrm{~m} / 3 / \mathrm{s}$ for the river and $0.050 \mathrm{~m}^{1 / 3} / \mathrm{s}$ for the floodplain area, for use in all simulations.

Those values came from a previous calibration of the hydraulic model in a similar floodplain area close to the study area. In detail, the calibration was performed through Monte Carlo simulations using both the measured inundation depths and the flow velocities deduced from video analysis of the event. Friction values, in terms of Manning's $\mathrm{n}$ value, were randomly and uniformly distributed between $0.035 \mathrm{~m}^{1 / 3} \mathrm{~s}^{-1}$ and $0.1 \mathrm{~m}^{1 / 3} \mathrm{~s}^{-1}$ for the river, and between $0.045 \mathrm{~m}^{1 / 3} \mathrm{~s}^{-1}$ and $0.2 \mathrm{~m}^{1 / 3} \mathrm{~s}^{-1}$ for the floodplain. The errors between the observed and predicted outputs, called the residuals, were formulated in terms of residual sum of squares (SSR) and the root mean square error (RMSE) of the simulation results from the measured inundation depths (WD). More details about model calibration can be found in [21].

The flood hydrographs used for the hydraulic simulations were obtained by using a conceptual rainfall runoff model developed by [22]. The model used is a very simple one, with a limited number of parameters, which practically does not require any calibration, resulting in a robust tool for those catchments that are partially or poorly gauged.

The model is based on three modules: a stochastic rainfall generator module, a hydrologic loss module, and a flood routing module. In the rainfall generator module, the rainfall storm, i.e., the maximum rainfall depth for a fixed duration, is assumed to follow the two components' extreme value (TCEV) distribution, whose parameters have been estimated at regional scale for Sicily. The catchment response was modeled by using the Soil Conservation Service curve number (SCS-CN) method for the transformation of total rainfall to effective rainfall, while a simple form of the instantaneous unit hydrograph was used for the flood routing.

Application of this model to the Mela catchment allowed the flood frequency curve (FFC) to be derived, which relates the maximum peak flow to the corresponding value of the return period $\mathrm{T}$, as shown in Figure 4.

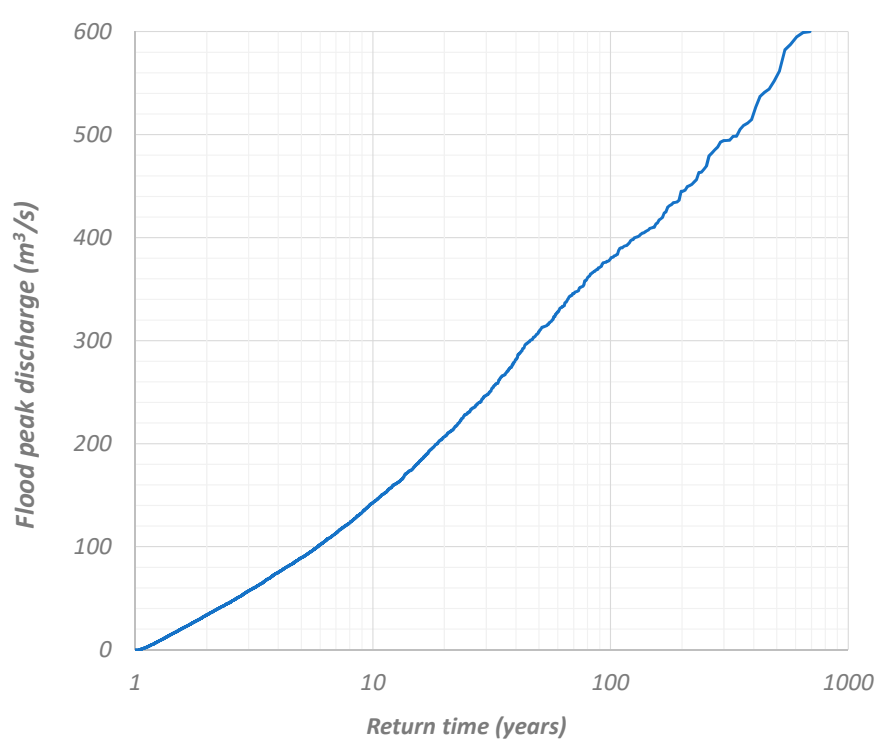

Figure 4. Flood frequency curve for the Mela catchment. 
As an example, in Table 1 the maximum flood peak discharges for 50, 100, 200, and 300 years are reported. Finally, flood hydrographs are considered in a triangular shape with a center peak equal to the maximum flood discharge and a duration equal to twice the concentration time of the catchment.

Table 1. Values of peak discharges $Q$ for different return times T from the FFC (flood frequency curves).

\begin{tabular}{ccccc}
\hline $\mathbf{T}$ (years) & 50 & 100 & 200 & 300 \\
\hline $\mathbf{Q}\left(\mathbf{m}^{\mathbf{3}} / \mathbf{s}\right)$ & 308 & 379 & 445 & 494 \\
\hline
\end{tabular}

In order to assess the direct damage caused by the flooding of agricultural areas, starting from the knowledge of the land use classes of the area of interest, the following procedure based on the use of damage functions was implemented. The functions, shown in Figure 5, which associate water depths with the rate of damage for different categories of crops and based on "new" costs (replacement) and productivity costs, were proposed by ISPRA-JRC (Joint Research Centre) [16,23].

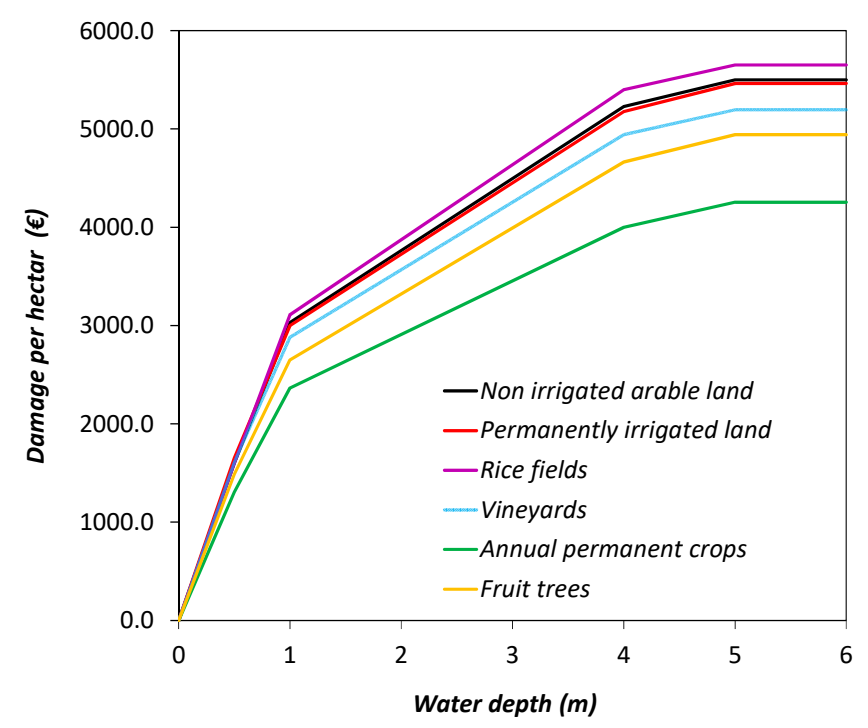

Figure 5. Damage related to water depth for agricultural areas.

The determination of the purchasing power parity (PPP) was carried out through the consultation of the National Institute of Agricultural Economics (INEA) reports in order to estimate the values of agricultural areas with the same purchasing power for the province of Messina (Table 2) [24]. The results are represented by the "water depth-damage" mean functions, thus expressing the damage in terms of euro $/ \mathrm{m}^{2}$ with the same purchasing power.

As the damage is expressed in relative units (per square meter), the calculation was carried out by averaging the water depths at the finite element scale. Specifically, a unique value for each element was calculated by averaging the three nodal values, and given the element area and the crop category associated with the element, the total damage was obtained.

Table 2. Monetary values of agricultural areas and crops in the study area.

\begin{tabular}{ccccccc}
\hline \multirow{2}{*}{ Altimetry } & \multicolumn{7}{c}{ Value/Hectare (Euros) } \\
\cline { 2 - 7 } & Non Irrigated Arable Land & Rice Fields & Fruit Trees & Olive Grove & Meadows & Woods \\
\hline Mountains & 7414 & - & 7182 & 10,800 & 2806 & 5083 \\
Hills/Plains & 25,864 & 86,033 & 39,567 & 20,462 & 3229 & 2100 \\
\hline
\end{tabular}


Concerning the damage to buildings in the residential areas of Bastione and Caldà, the procedure proposed by [17] was used.

Particularly, the procedure assesses damages for buildings based on their exposure classes and the relationship between the flood depth and vulnerability in order to evaluate flood consequences in those situations where vulnerability data do not exist or their quality makes them unreliable. The curves for the quality of three classes of materials (expensive finishes for the building types such as villas and cottages; medium finishes for flats and single houses inside towns; and inexpensive finishes for detached houses and single houses in villages.) were derived based on the replacement costs. The passage from inexpensive to expensive materials, as expected, corresponds to a decrease in relative damage, as better quality materials suffer less flood damage compared to low-quality ones. In addition, the different replacement costs are weighted differently with respect to the total costs.

Here, the discretization of different classes of finishes was useful for entering the vulnerability curves obtained for the same finishing classes of buildings in the risk area, depending on the replacement costs of potentially damaging elements related to the value of the water depth reached (Figure 6).

The first step of the analysis consisted of deciding which buildings' classes were to be included-this distinction only refers to the building type, because the function was already considered through the buildings' exposure levels. The same curves can be used for buildings with the same construction features, even if they have different functions, such as residential or commercial. On the other hand, different curves should be used for buildings with the same functions but with different construction features.

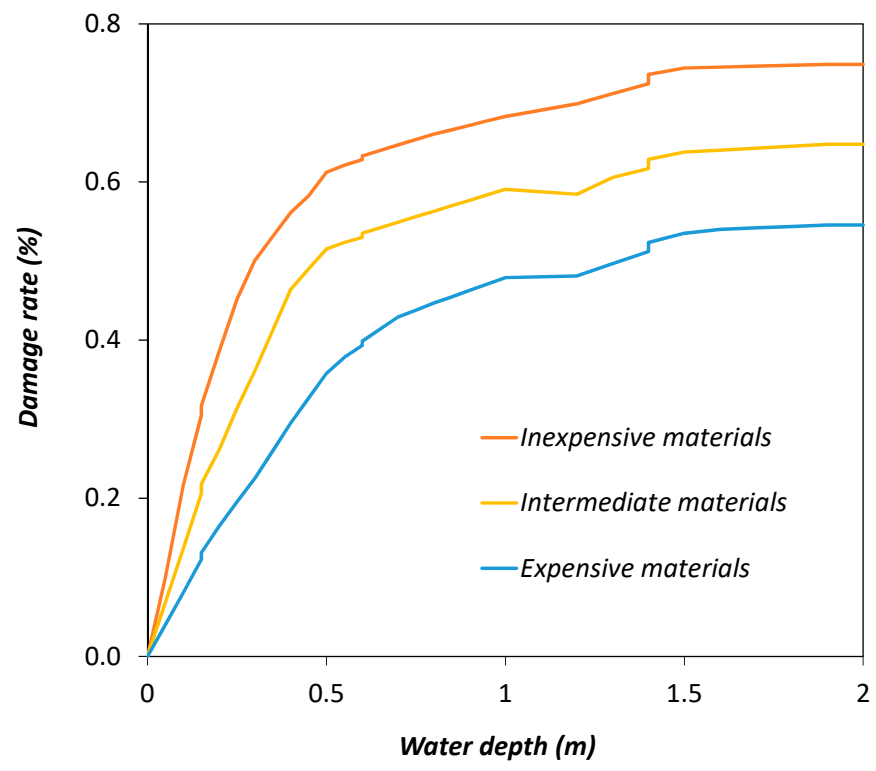

Figure 6. Damage related to water depth for buildings (adapted from [21]).

Given the characteristics of the buildings located in the flooded area, the intermediate material curve was assumed corresponding to the following characteristics: a standard room measuring 20 $\mathrm{m}^{2}$ with a door, a 90-cm-high French window, 5 electrical sockets positioned $30 \mathrm{~cm}$ from the floor, 2 switches, other 3 sockets positioned $110 \mathrm{~cm}$ from the floor, a gas tap for the kitchen positioned $60 \mathrm{~cm}$ from the floor, and a gas tap for the boiler positioned $140 \mathrm{~cm}$ from the floor (Figure 7). 


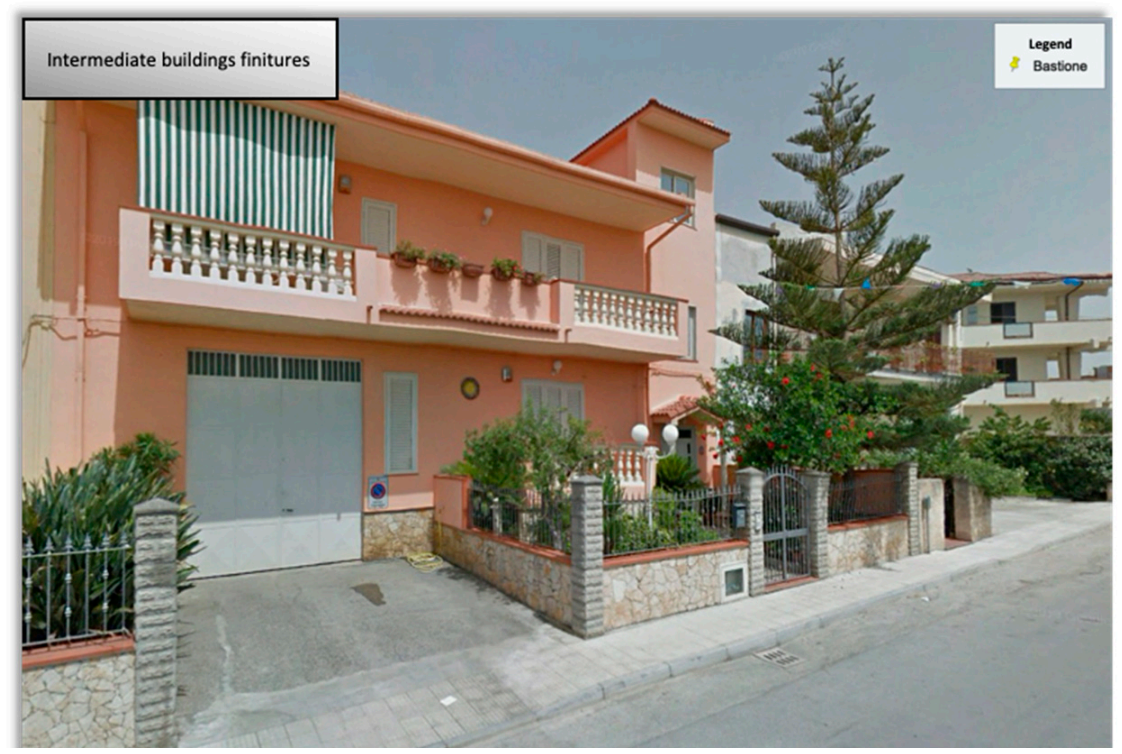

Figure 7. Example building with intermediate finishes.

In Table 3, the building elements' weights are reported for the intermediate class.

Table 3. Damage to intermediate building finishes related to water depth.

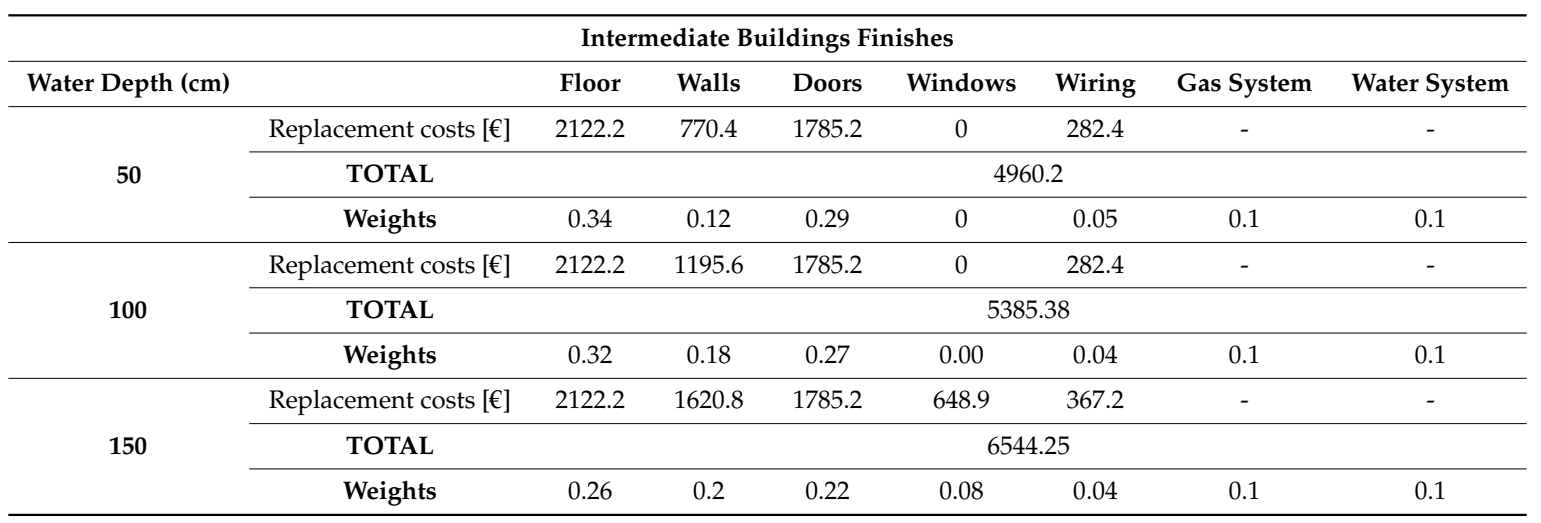

For the implementation of the cost-benefit analysis, the following steps were performed:

- Simulations with the MLFP-2D model of the inundation map were performed for the reference return time, the value of which was equal to 100 years, as this is the reference for the design of the flood protection measures according to the Flood Defense Plan for Sicily [21];

- Vulnerability assessment using water depth-damage percentage curves for the considered flooding scenario;

- Calculation of the total associated damage (agricultural + built-up);

- Calculation of the benefits compared to a base scenario (no intervention).

Regarding this base scenario, in Figure 8 the inundation map with the spatial distribution for the water depths for the reference return time is shown. Using the information from the Corine Land Cover Project, it was also possible to draw a map (Figure 9) of the exposed assets (agricultural and built-up areas, infrastructure, etc.). 


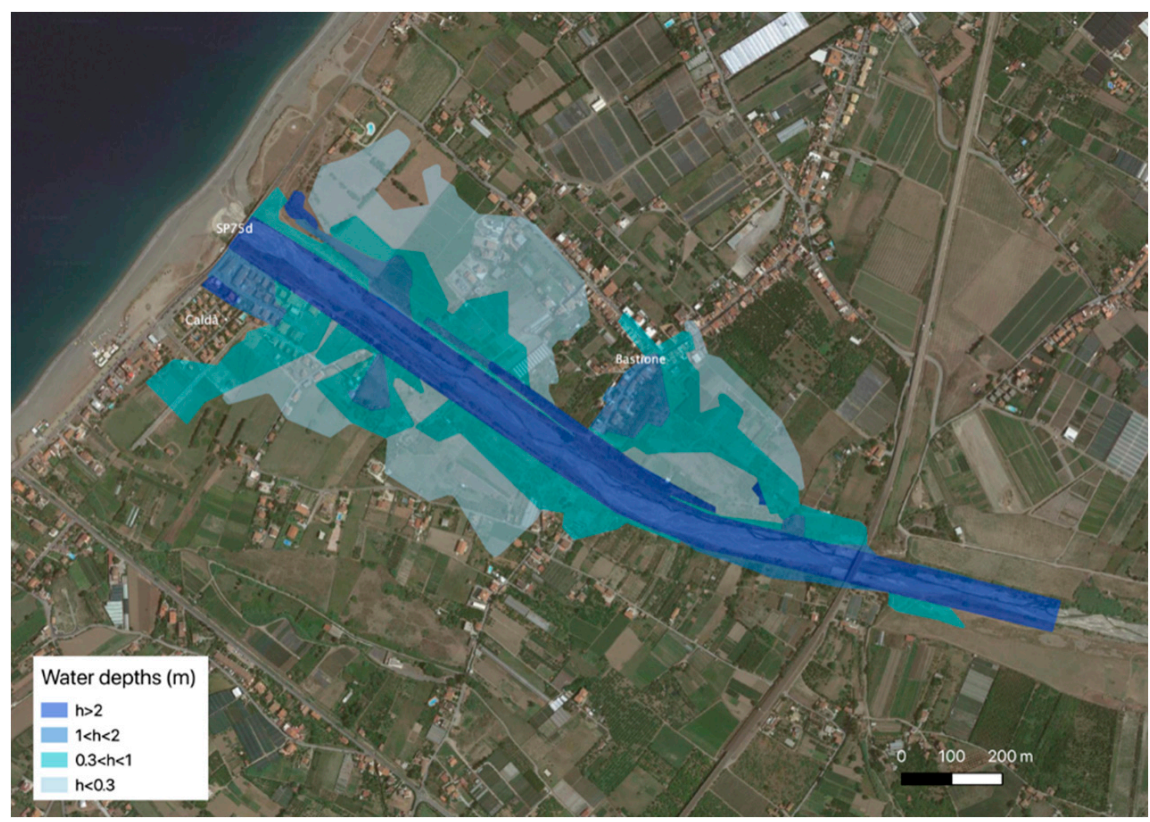

Figure 8. Inundation map for return time $\mathrm{T}=100$ years for different water depths (no intervention scenario).

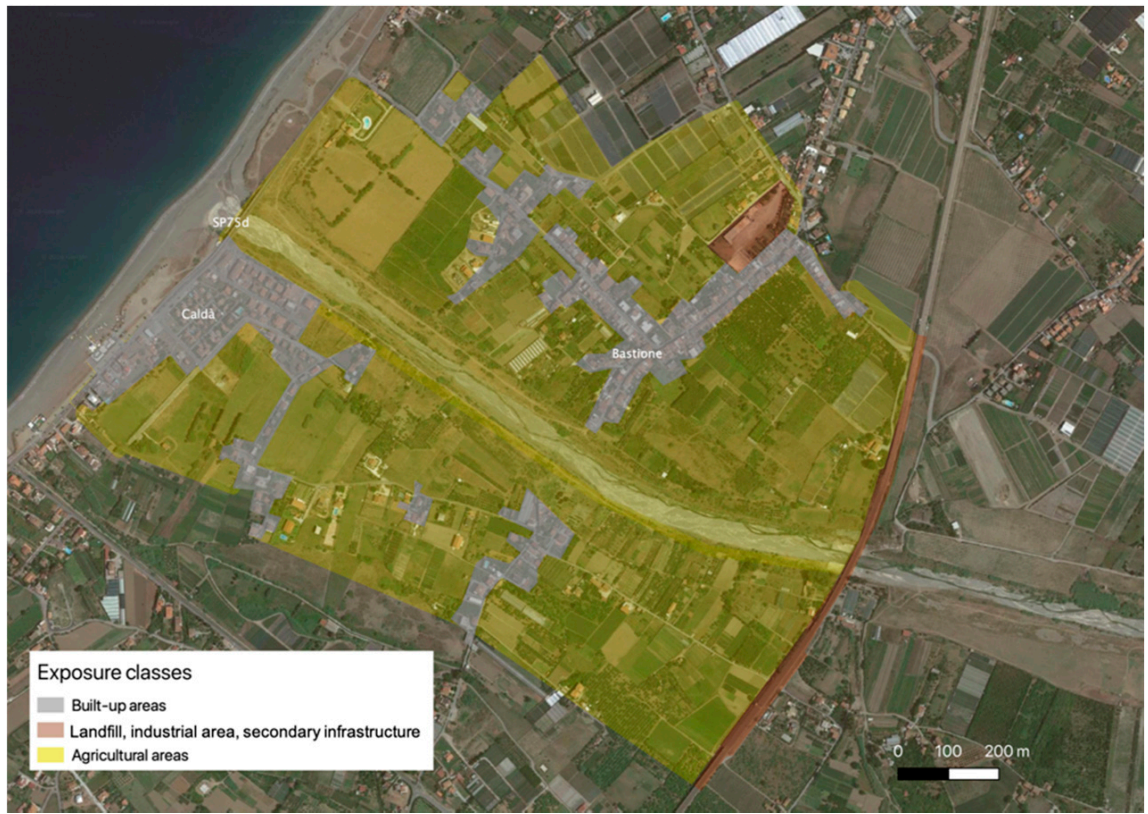

Figure 9. Exposure classes for the study area.

The total flooded area was around $0.39 \mathrm{~km}^{2}$, of which $0.26 \mathrm{~km}^{2}$ covered agricultural areas and $0.13 \mathrm{~km}^{2}$ covered built-up areas. The damage equaled about 0.60 MEuro (million euros) for the built-up areas and about 0.29 MEuro for the agricultural areas, giving a total damage value of 1.04 MEuro.

Further, by overlaying both the inundation map and exposure map, the risk map was derived (Figure 10). The risk classification (low, moderate, high, very high) follows the specifications of the Flood Defense Plan for Sicily [21]. This map was used as the basis for the definition of the mitigation measures scenarios for which the CBA was implemented. 


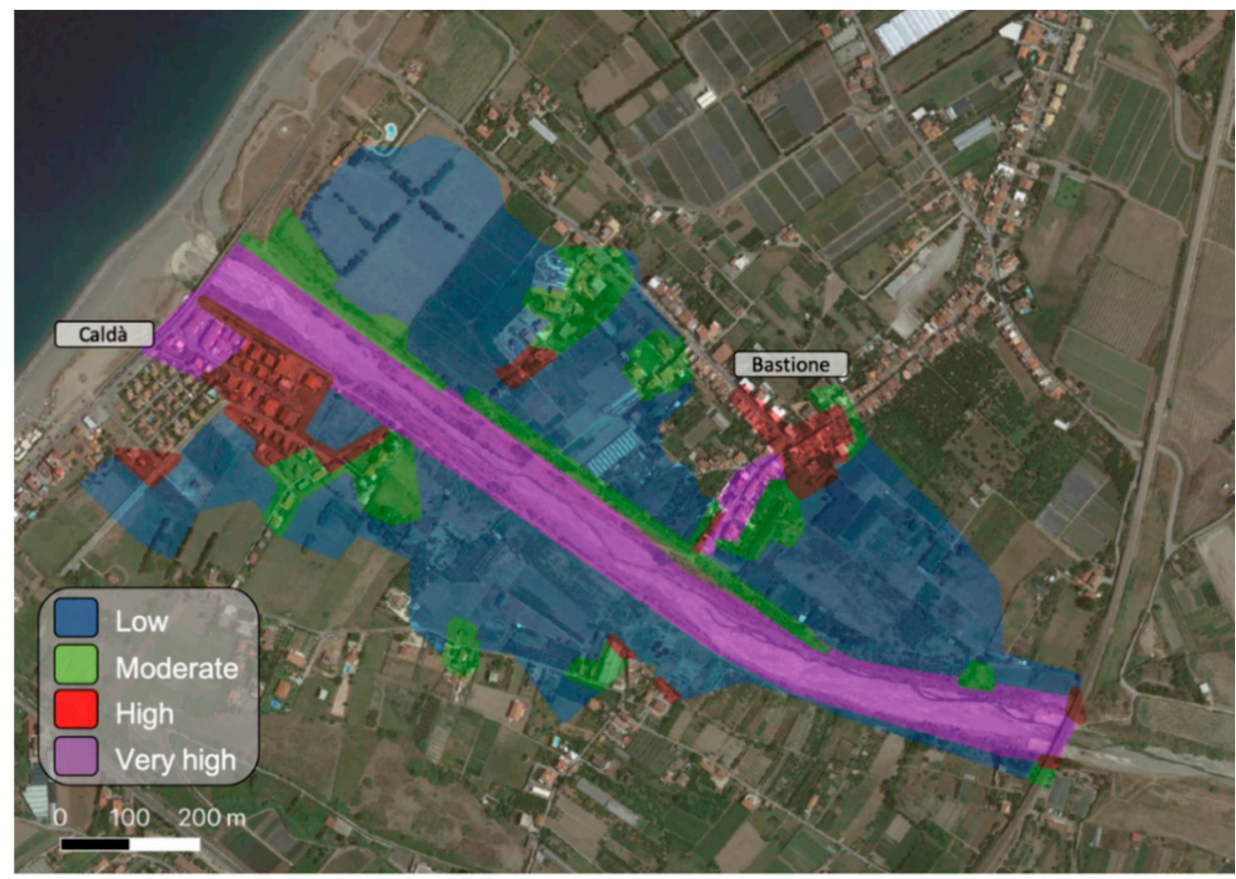

Figure 10. Flood risk map for the study area.

Scenario 1: Revamping of the existing levees along the watercourse.

The first type of intervention (Scenario 1) consists of the reconstruction of a concrete levee with a height of $250 \mathrm{~cm}$ in order to contain the floodwaters in the river.

The location of the intervention coincides with two breaches, through which floodwater flowed and inundated the neighboring agricultural fields and the houses in the residential areas of Calda and Bastione during the 2015 flooding event.

The new levee is supposed to be built with a total length of about $1300 \mathrm{~m}$, located on both sides of the river course-about $550 \mathrm{~m}$ on the right side of the river immediately downstream of the railway line and upstream of the first village (Bastione), and about $600 \mathrm{~m}$ on the left side of the river close to the second village (Caldà) (Figure 11).

The cost calculation of this structural intervention was estimated by consulting the Official Regional Price List in order to give a trusted assessment. The main items relating to the construction process of the aforementioned work were selected, and therefore the costs inherent to the excavation; the open section or splitting excavation; and the concrete conglomerate for the structures, steel bars, and installation were also considered.

Therefore, it was possible to conduct the cost-benefit analysis (Figure 12), whereby the components of the investment costs, the flood damage in both urban and agricultural areas following the intervention, and the total cost were shown. It is noted that it is not possible to search for the minimum value of the function, due to the high cost of implementation compared to the overall damage caused. In this scenario, the expected damage was reduced significantly for the village areas, while some agricultural areas close to the railway remain subject to flooding, but with more limited water depths. 


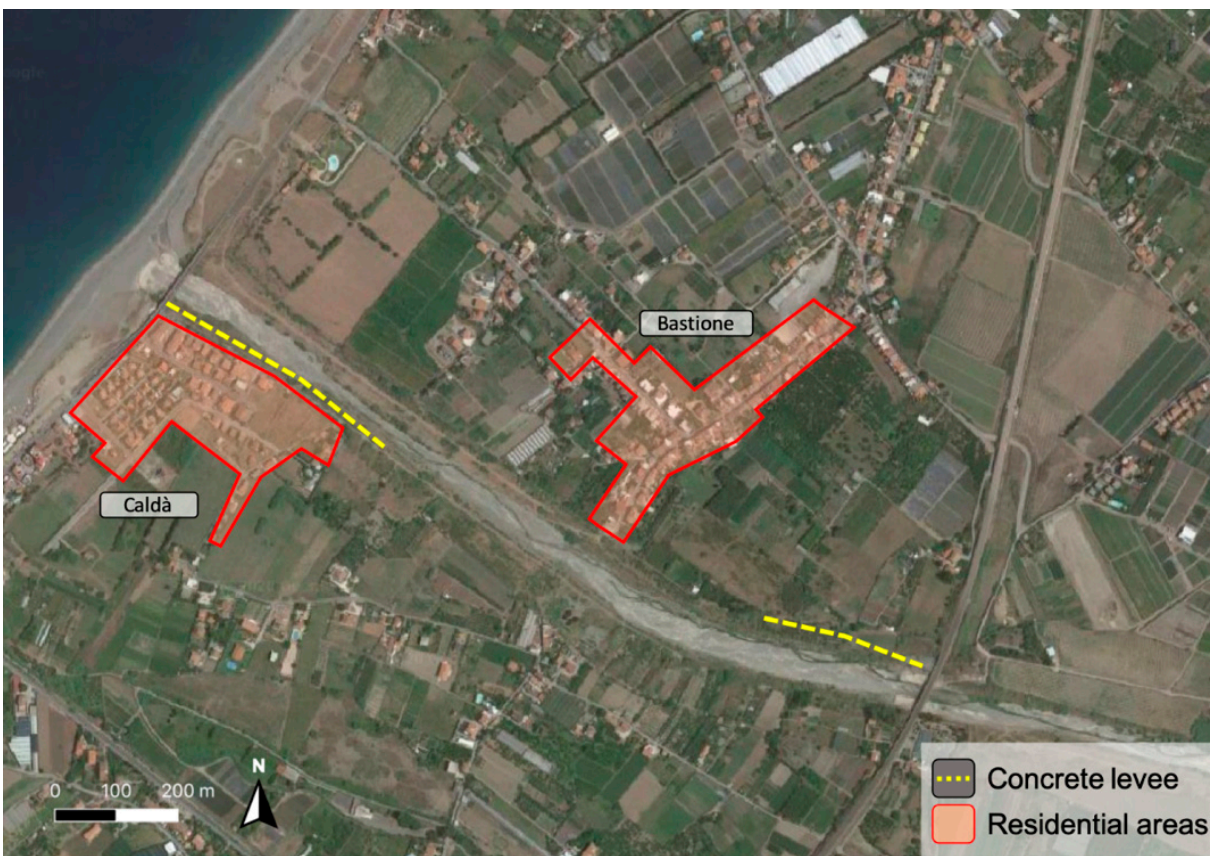

Figure 11. Scenario 1: intervention location.

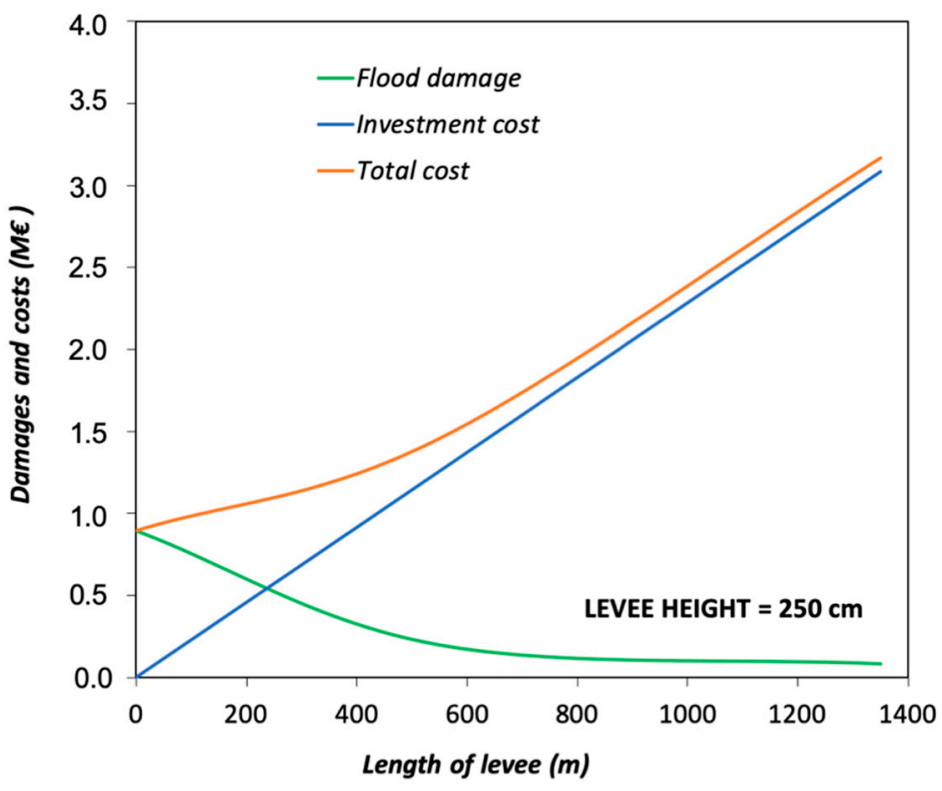

Figure 12. Cost-benefit analysis for scenario 1.

Regarding the other two scenarios (namely 2 and 3) where flood proofing solutions were implemented, their final locations and sizes (barrier heights) were chosen by trying to optimize the reduction of the extension of the flooded areas and the water depths by focusing on the morphologies of the areas and the possible directions of the floodwater flow. In addition, information from the flood risk map was taken into account (Figure 10).

Scenario 2: Installation of flood barriers of different sizes (heights of 150 and $250 \mathrm{~cm}$ ).

The second type of intervention concerns the installation of flood barriers of different sizes (heights). The selected barrier heights were 150 and $250 \mathrm{~cm}$. Following the above considerations, the locations of the interventions were chosen, as shown in Figure 13. 

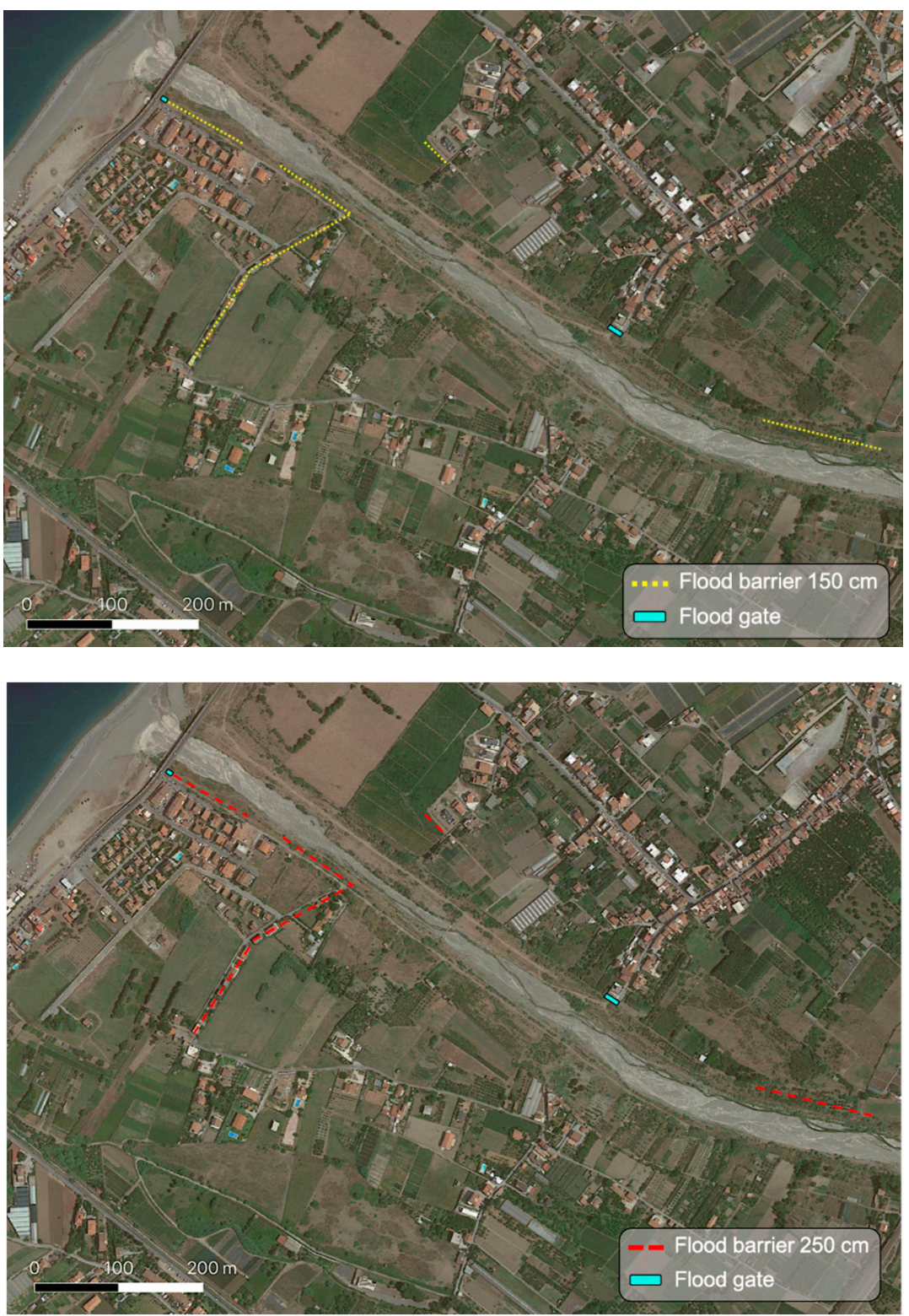

Figure 13. Locations of flood barriers: (top): $150 \mathrm{~cm}$ height; (bottom): $250 \mathrm{~cm}$ height.

The cost-benefit analysis was carried out separately for the 150 and $250 \mathrm{~cm}$ barriers, the results for which are reported in Figure 14.

The use of barriers with a height of $150 \mathrm{~cm}$ shows how it is possible to reduce the damage, however this can increase again due to the morphology of the land, which allows an increase of the water depth overcoming the barriers in some sections. This causes flooding of some parts of the residential area and surrounding cultivated areas, causing an increase of the water depths, with a consequent increase of the expected damage. Considering barriers with a height of $250 \mathrm{~cm}$, a greater reduction of inundated area was observed, and consequently a greater reduction of the total damage. Conversely, the investment costs are greater. However, using barriers with a height of $150 \mathrm{~cm}$ is always better than any combined solution. Considering the barriers with a height of $250 \mathrm{~cm}$, the total damage was reduced by about $50 \%$ more than was observed for the barriers considered previously (Figure 14). 

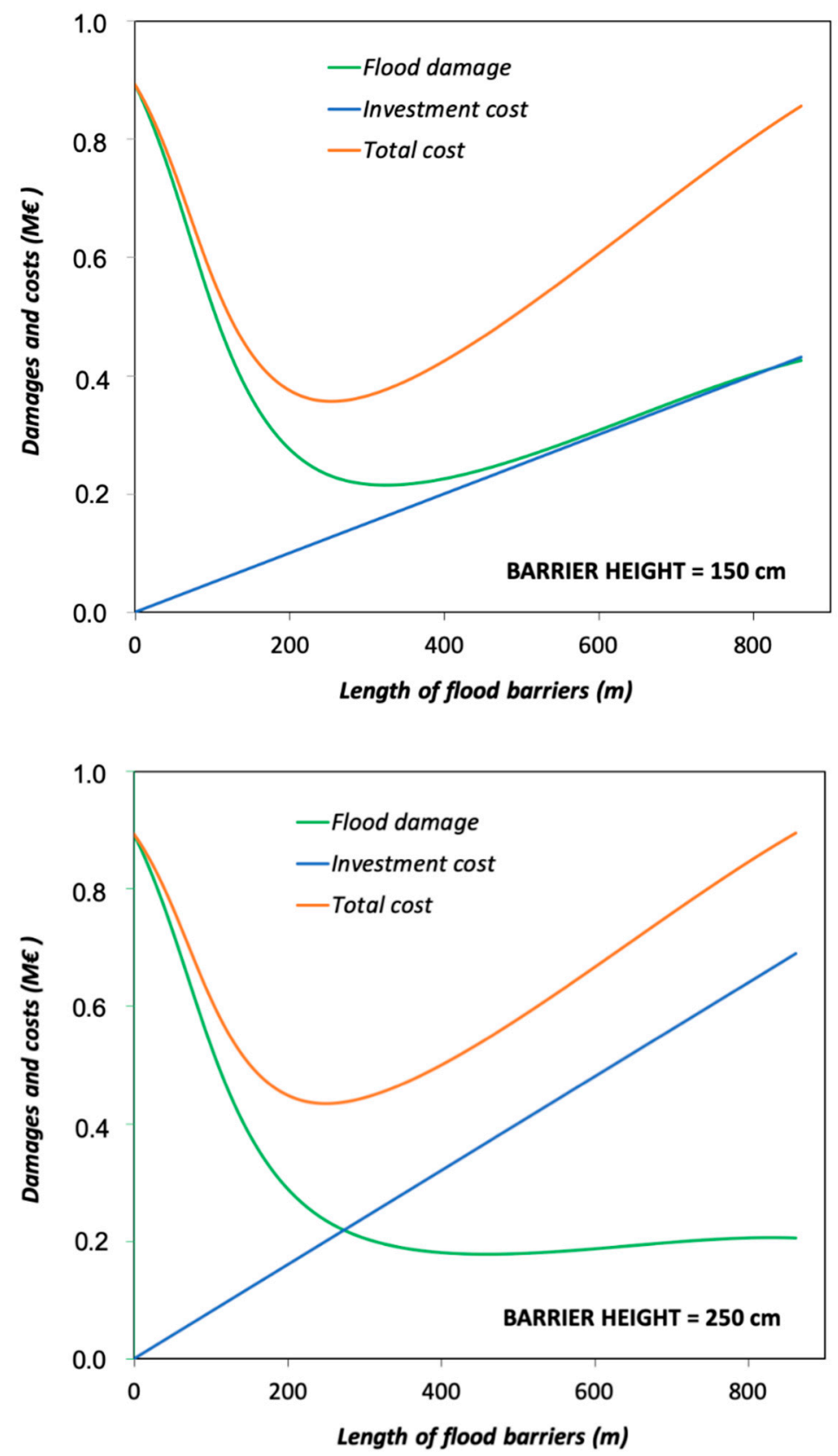

Figure 14. Cost-benefit analysis for scenario 2 ((top): barrier height $=150 \mathrm{~cm}$; (bottom): barrier height $250 \mathrm{~cm})$.

\section{Scenario 3: Installation of flood doors and flood windows.}

The third type of intervention deals with the use of flood doors and flood windows (Scenario 3). In this case, the interventions will be implemented only for the defense of individual houses (and buildings in general) affected by a flood. The cost-benefit analysis (Figure 15) identified a minimum value for the total cost function. The reductions in terms of damage were lower than in the two previous scenarios, because it is inevitable to have external damage to houses. 


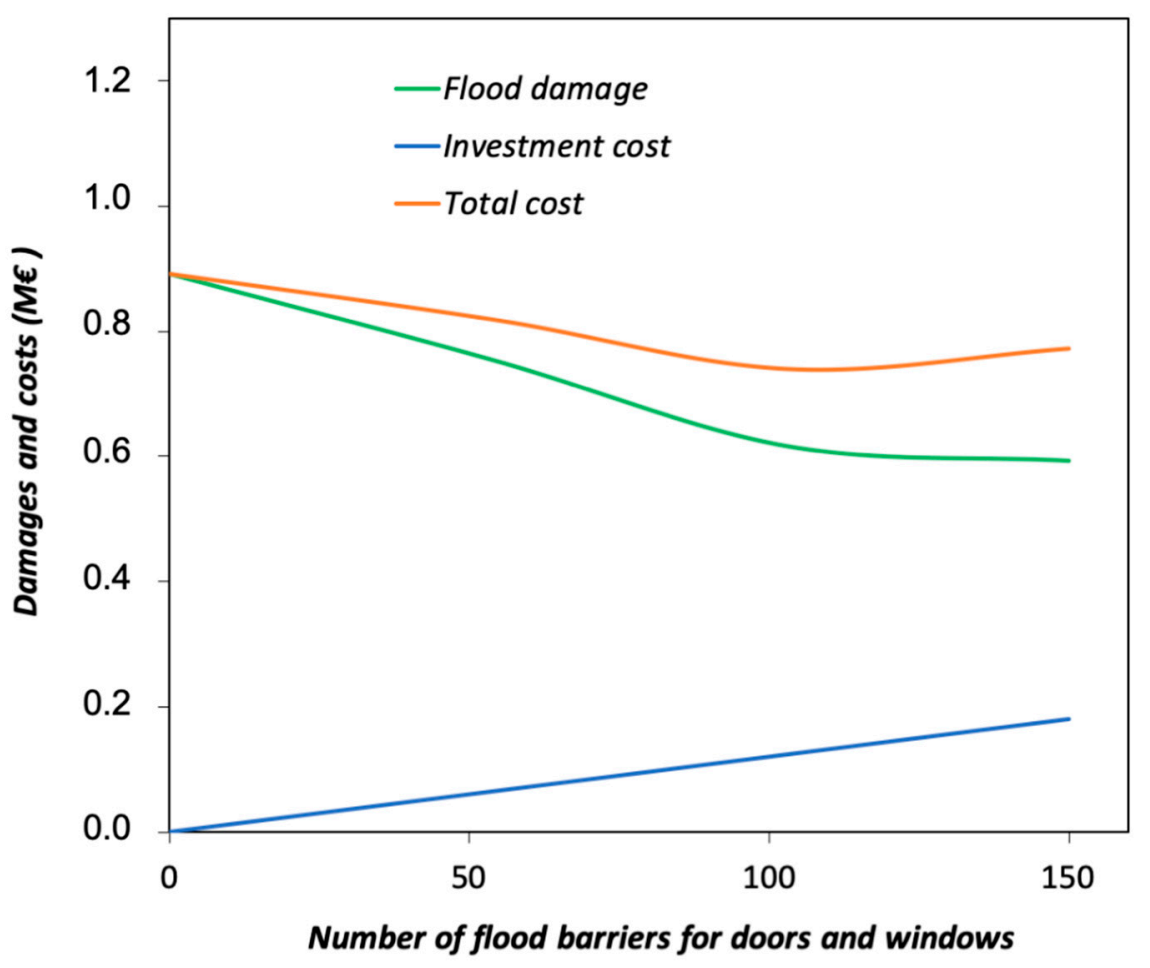

Figure 15. Cost-benefit analysis for scenario 3.

\section{Conclusions}

In this study, a methodology for assessing the real effectiveness of different flood proofing measures was set up through a cost-benefit analysis, starting from an estimate of the direct flood damage in both urban and agricultural areas. The proposed approach has been tested on a real case study, the Mela catchment, which was affected by a flood event in October 2015 that caused considerable damage. Flood risk scenarios have been produced for the Mela river under one extreme flood event and different mitigation risk scenarios.

Due to the precise definition of the implemented flood proofing measures, their costs could be assessed using a cost-benefit analysis (CBA) for buildings and cultivated areas.

Damage analyses for all scenarios revealed how each measure (in terms of position, characteristics, size, etc.) can directly reduce the negative effects of flooding in the downstream floodplain. We focused on two measures aimed at reducing the vulnerability of existing buildings to floods (precautionary measures) and analyzed their cost efficiency levels. The construction of a concrete levee, a common and traditionally used type of intervention, highlighted how the reduction of the expected flood damage can be decreased significantly.

However, this reduction has considerable investment costs, meaning the adoption of such a mitigation measure is not justified in this case study. In this regard, the results of the CBA analysis show that it is not possible to look for the minimum value of the function for this case.

Scenario 2 involves a comparison between two different types of barriers, with heights of 150 and $250 \mathrm{~cm}$. The CBA analysis carried out for scenario 2 on the use of barriers with different heights showed that with both types it is possible to observe the minimum value of the function.

Finally, for single houses, it would be appropriate to use specific interventions such as flood doors and windows (Scenario 3) in order to reduce the cost per unit/meter of the flood barriers.

The overall results provide the basis for the application of the proposed approach in other flood risk areas and support the decision-making processes of the agencies and authorities toward more resilient risk mitigation measures. 
Author Contributions: Data curation, U.V.; Formal analysis, U.V., A.C. and G.T.A.; Supervision, A.C. and G.T.A. All authors have read and agreed to the published version of the manuscript.

Funding: U.V. is supported by University of Messina Ph.D Grant for Civil and Environmental Engineering.

Acknowledgments: The authors wish to thank Biagio Privitera (Civil Protection Office of Messina Metropolitan City) for supplying the post-event survey data.

Conflicts of Interest: The authors declare no conflict of interest.

\section{References}

1. Munich, R.E. Natural Catastrophe Review: Series of Hurricanes Makes 2017 Year of Highest Insured Losses Ever, Munich RE. 4 January 2018. Available online: https://www.munichre.com/en/company/media-relation s/media-information-and-corporate-news/media-information/2018/2018-01-04-natural-catastrophe-revie W-series-of-hurricanes-makes-2017-year-of-highest-insured-losses-ever.html (accessed on 24 August 2020).

2. Jongman, B.; Ward, P.J.; Aerts, J.C. Global exposure to river and coastal flooding: Long term trends and changes. Glob. Environ. Chang. 2012, 22, 823-835. [CrossRef]

3. Webber, J.; Fu, G.; Butler, D. Comparing cost-effectiveness of surface water flood management interventions in a UK catchment. J. Flood Risk Manag. 2019, 12, e12523. [CrossRef]

4. Andjelkovic, I. Guidelines on Non-Structural Measures in Urban Flood Management; UNESCO: Paris, France, 2001.

5. Federal Emergecy Management Agency. Protecting Building Utility Systems from Flood Damage Principles and Practices for the Design and Construction of Flood Resistant Building Utility Systems, FEMA P-348. February 2017. Available online: https://www.fema.gov/media-library-data/1489005878535-dcc4b360f5c7eb 7285acb2e206792312/FEMA_P-348_508.pdf (accessed on 24 August 2020).

6. Federal Emergecy Management Agency. Six Way to Protect Your Home from Flooding, FEMA P-312. June 2014. Available online: https://www.fema.gov/media-library-data/1404148604102-f210b5e43aba0fb393443fe7 ae9cd953/FEMA_P-312.pdf (accessed on 24 August 2020).

7. Bouwer, L.M.; Bubeck, P.; Aerts, J.C.J.H. Changes in future floodrisk due to climate and development in a Dutch polder area. Glob. Environ. Chang. 2010, 20, 463-471. [CrossRef]

8. Linde, A.H.T.; Bubeck, P.; Dekkers, J.E.C.; De Moel, H.; Aerts, J.C.J.H. Future flood risk estimates along the river Rhine. Nat. Hazards Earth Syst. Sci. 2011, 11, 459-473. [CrossRef]

9. Feyen, L.; Dankers, R.; Bodis, K.; Salamon, P.; Barredo, J.I. Fluvial flood risk in Europe in present and future climates. Clim. Chang. 2011, 112, 47-62. [CrossRef]

10. Rojas, R.; Feyen, L.; Watkiss, P. Climate change and river floods in the European Union: Socio-economic consequences and the costs and benefits of adaptation. Glob. Environ. Chang. 2013, 23, 1737-1751. [CrossRef]

11. Jongman, B.; Kreibich, H.; Apel, H.; Barredo, J.I.; Bates, P.D.; Feyen, L.; Gericke, A.; Neal, J.C.; Aerts, J.C.J.H.; Ward, P.J. Comparative flood damage model assessment: Towards a European approach. Nat. Hazards Earth Syst. Sci. 2012, 12, 3733-3752. [CrossRef]

12. Linham, M.M.; Green, C.H.; Nicholls, R.J. Costs of Adaptation to the Effects of Climate in the World's Largest Port Cities; AVOID: London, UK, 2010; p. 225.

13. Lasage, R.; Veldkamp, T.I.E.; de Moel, H.; Van, T.C.; Phi, H.L.; Vellinga, P.; Aerts, J.C.J.H. Assessment of the effectiveness of flood adaption strategies for HCMC. Nat. Hazards Earth Syst. Sci. 2014, 14, 1441-1457. [CrossRef]

14. Federal Emergecy Management Agency. Flood Proofing Non-Residential Buildings, FEMA P-936. July 2013. Available online: https://www.fema.gov/media-library-data/1541615774329-170190ea05ddbbb6fdc5f1170a01 8d41/P-936_11-06-18_508r.pdf (accessed on 24 August 2020).

15. Hanley, N.; Splash, C.L. Cost of Benefit Analysis and the Environment; Edward Elgar Publishing Ltd.: Cheltenham, UK, 1993.

16. Huizinga, H.J. Flood Damage Functions for EU Member States. HKV Consultants, Technical Report Implemented in the Framework of the Contract \# 382441-F1SC Awarded by the European Commission-Joint Research Centre. 2007. Available online: https://publications.jrc.ec.europa.eu/repository/bitstream/JRC105688/global_flood_depthdamage_functions_10042017.pdf (accessed on 24 August 2020).

17. Naso, S.; Chen, A.S.; Aronica, G.T.; Djordjević, S. A novel approach to flood risk assessment: The ExposureVulnerability matrices, Proocedings of FLOODrisk 2016. In Proceedings of the 3rd European Conference on Flood Risk Management, Lyon, France, 17-21 October 2016. 
18. Rappazzo, D.; Aronica, G.T. Effectiveness and applicability of flood barriers for risk mitigation in flash-flood prone Mediterranean area, Documents of FLOODrisk 2016. In Proceedings of the 3rd European Conference on Flood Risk Management, Lyon, France, 17-21 October 2016.

19. Aronica, G.T.; Tucciarelli, T.; Nasello, C. A 2D Multilevel Model for Flood Propagation in Flood Affected Areas. J. Water Resour. Plan. Manag. 1998, 124, 210-217. [CrossRef]

20. Candela, A.; Aronica, G.T. Probabilistic Flood Hazard Mapping Using Bivariate Analysis Based on Copulas. J. Risk Uncertain. Eng. Syst. Part A Civ. Eng. 2017, 3. [CrossRef]

21. Naso, S. Novel Approaches for Flood Risk Assessment Using Exposure-Vulnerability. Ph.D. Thesis, University of Palermo, Palermo, Italy, 2017.

22. Aronica, G.T.; Candela, A. Derivation of flood frequency curves in poorly gauged Mediterranean catchments using a simple stochastic hydrological rainfall-runoff model. J. Hydrol. 2007, 347, 132-142. [CrossRef]

23. Rusmini, M. Pan-European Flood Hazard and Damage Assessment; Evaluation of a New If-SAR Digital Terrain, Model for Flood Depth and Flood Extent Calculation; International Institute for Geo-Information Science and Earth Observation: Enschede, The Netherlands, 2009.

24. Gioia, M.; Mari, F. Il Valore della Terra: Un Contributo alla Conoscenza del Mercato Italiano dei Terreni Agricoli Attraverso i Dati della RICA; INEA: Rome, Italy, 2012.

(C) 2020 by the authors. Licensee MDPI, Basel, Switzerland. This article is an open access article distributed under the terms and conditions of the Creative Commons Attribution (CC BY) license (http://creativecommons.org/licenses/by/4.0/). 